Конструкція і теорія сільськогосподарських машин Construction and theory of agricultural machines

\title{
Вільні коливання осцилятора Дуфрфінгу з сухим тертям
}

\author{
В.П. Ольшанський ${ }^{1}$, В.В. Бурлака ${ }^{2}$, М.В. Сліпченко ${ }^{3}$ \\ Харківський національний технічний університет сільського господарства \\ імені Петра Василенка (м. Харків, Україна) \\ email: 1 OlshanskiyVP@gmail.com, ${ }^{2}$ Burlaka2V@ukr.net, ${ }^{3}$ Slipchenko_M@ukr.net \\ ORCID: ${ }^{1}$ 0000-0003-1407-4476, ${ }^{2}$ 0000-0001-9437-1950, ${ }^{3}$ 000-0002-9728-661X
}

\begin{abstract}
Описано вільні затухаючі коливання осцилятора з сухим тертям Кулона при наявності лінійного та кубічного доданків у виразі відновлюючої сили, яка залежить від переміщення системи. Використовуючи перший інтеграл нелінійного диференціального рівняння руху, визначення точних значень амплітуд розмахів зведено до обчислення відповідних дійсних коренів кубічного рівняння, що має аналітичну реалізацію. Для наближеного обчислення значень амплітуд запропонована також додаткова компактна ітераційна формула. Задовільна збіжність ітерацій по ній підтверджена чисельними розрахунками. Розв'язана також задача визначення тривалостей розмахів. Для цього переходом до нових змінних інтегрування невласний інтеграл другого роду зведено до суми двох власних інтегралів, що виражають тривалість розмаху в часі. Їх доводиться інтегрувати чисельними методами на комп'ютері. Тому додатково подано нерівності для двобічної оцінки тривалостей розмахів та запропонована компактна формула, що дає можливість наближено обчислити цю тривалість. Проведено порівняння числових результатів, одержаних різними способами. Показано, що затухання амплітуд коливань, тривалості розмахів у часі їх кількість до повної зупинки осцилятора залежать від характеристик нелінійності. Встановлено, що у зв'язку з нелінійною пружністю, тривалості розмахів осцилятора Дуффінга залежать від амплітуд коливань. Від характеристик нелінійності також залежить і ширина області застою осцилятора, визначення якої зведено до обчислення дійсного кореня кубічного рівняння за фрормулами Кардано. Виведені формули дають можливість без використання другого інтегралу нелінійного рівняння коливань осцилятора обчислити його основні кінематичні характеристики, які змінюються в ході руху.
\end{abstract}

Ключові слова: вільні затухаючі коливання, осцилятор Дуффрінга, сухе тертя, амплітуди розмахів, тривалість розмахів, інтегральні оцінки.

Вступ. Незважаючи на суттєві досягнення в теорії нелінійних коливань і тепер продовжує активно розвиватись ця область нелінійної механіки. Свідченням тому $€$ монографічні видання [1-4], де надруковано чималі списки літературних джерел і проведено їх відповідний огляд. Питання затухання вільних коливань, при дії різних дисипативних сил, висвітлено також в [5-8] та інших публікаціях.

Аналіз літературних даних та постановка проблеми. Осцилятор Дуффінга відноситься до класичних нелінійних коливальних систем. При дослідженні його руху апробовано чимало методів нелінійної механіки [9-11]. В даній роботі зроблена спроба з'ясувати особливості його руху при дії сили сухого тертя, використовуючи точні та наближені розв'язки задачі. Для аналізу руху задіяно лише перший інтеграл рівняння коливань, чого достатньо для обчислень максимальних відхилень системи від положення статичної рівноваги та визначення ширини області застою.

Метою роботи $є$ виведення та апробація формул для обчислення амплітуд і тривалостей розмахів при «жорсткій» та «м'якій» пружностях системи з одним ступенем вільності, в умовах дії сили сухого тертя.

Основна частина роботи. Вільні коливання системи, зумовлені початковим відхиленням її від положення статичної рівноваги, описуємо диференціальним рівнянням:

$$
\ddot{x}+\omega^{2} x+\lambda x^{3}=-f g \operatorname{sign}(\dot{x})
$$

при початкових умовах:

$$
x(0)=-a_{0} ; \dot{x}(0)=0
$$


B (1), (2) $\omega^{2}=c_{1} / m ; \lambda=c_{2} / m ; c_{1}, c_{2}$ - характеристики пружності системи; $m$ - маса осцилятора; $f$ - коефіцієнт сухого тертя; $g$ - прискорення вільного падіння; $x=x(t)$ - коливальне переміщення системи; $a_{0}$ - початкове відхилення осцилятора від положення рівноваги в бік від'ємних значень на осі $o x$; $t$ - час; крапка над $x$ означає похідну по $t$.

Обчислення ширини області застою. Оскільки осцилятор припиняє рух в області застою $x \in\left[-a_{*} ; a_{*}\right]$, обчислимо величину $a_{*}$. Для цього треба розв'язати кубічне рівняння:

$$
\lambda a_{*}^{3}+\omega^{2} a_{*}-f g=0,
$$

У випадку лінійної пружини, коли $\lambda=0$, маємо:

$$
a_{*}=\frac{f g}{\omega^{2}}
$$

що давно відомо в теорії коливань.

Якщо пружина осцилятора нелінійно «жорстка» $(\lambda>0)$, то єдиний дійсний корінь рівняння (3) додатній і його досить просто обчислити по фрормулі:

$$
a_{*}=\sqrt[3]{\sqrt{q^{2}-p^{3}}-q}-\sqrt[3]{\sqrt{q^{2}-p^{3}}+q},
$$

де

$$
q=-\frac{1}{2} \frac{f g}{\lambda} ; p=-\frac{1}{3} \frac{\omega^{2}}{\lambda} .
$$

До формули (5) приводить відомий розв'язок кубічного рівняння в формі Кардано [12].

При «м'якій» нелінійності пружини осцилятора $(\lambda<0)$ рівняння (3) має три дійсних кореня. Менший з додатних коренів $a_{*}$ теж просто знайти по формулі:

$$
a_{*}=\sqrt{\left(\frac{\beta}{2}\right)^{2}-\frac{\omega^{2}+\lambda \beta^{2}}{\lambda}}-\frac{\beta}{2},
$$

в якій

$$
\beta=2 \sqrt{p} \cos \frac{\alpha}{3} ; \alpha=\pi-\arccos \frac{q}{\sqrt{p^{3}}} .
$$

Крім викладених точних розв'язків, корінь $a_{*}$ рівняння (3) можна також обчислювати наближеними методами. Одним із них $є$ метод простих ітерацій по формулі:

$$
a_{* k} \approx \frac{f g}{\omega^{2}+\lambda a_{* k-1}^{2}}, k=1,2,3, \ldots
$$

Незалежно від знака $\lambda$ за початкове наближення в фрормулу (7) можна підставити $a_{* 0} \approx 0$.
Рух осцилятора припиняється, якщо амплітуда відхилення ј-го розмаху при $\dot{x}=0$ стане задовольняти нерівності:

$$
a_{j} \leq a_{*} .
$$

Тому при початкових умовах (2) вважаємо, що $a_{0}>a_{*}$

Виведення формул для обчислень амплітуд розмахів. Під час руху на першому розмасі, коли $-a_{0} \leq x \leq a_{1}, \dot{x}>0$ і рівняння (1) набуває вигляд:

$$
\ddot{x}+\omega^{2} x+\lambda x^{3}=-f g,
$$

або

$$
v \frac{d v}{d x}=-f g-\omega^{2} x-\lambda x^{3}
$$

де $v=\dot{x}$

Проінтегрувавши (8) по $x$, одержуємо вираз швидкості руху:

$$
v=\sqrt{2} \sqrt{c_{3}-f g x-\frac{1}{2} \omega^{2} x^{2}-\frac{\lambda}{4} x^{4}},
$$

3 точністю до довільної сталої $c_{3}$.

Задовольнивши початковим умовам (2) знаходимо сталу $c_{3}$ і швидкість руху на першому розмасі:

$$
v=\sqrt{2} \cdot \sqrt{\frac{\lambda}{4}\left(a_{0}^{4}-x^{4}\right)+\frac{\omega^{2}}{2}\left(a_{0}^{2}-x^{2}\right)-f g\left(a_{0}+x\right)} .
$$

Структура цієї формули збережеться і для jго розмаху, коли $-a_{j-1} \leq x \leq a_{j}$, але матиме більш загальний вигляд:

$$
\begin{gathered}
|v|=\sqrt{2} \cdot\left(\frac{\lambda}{4} \cdot\left(a_{j-1}^{4}-x^{4}\right)+\right. \\
\left.+\frac{\omega^{2}}{2}\left(a_{j-1}^{2}-x^{2}\right)-f g\left(a_{j-1}+x\right)\right)^{\frac{1}{2}}
\end{gathered}
$$

Враховуючи, що в кінці ј-го розмаху $x=a_{j}$, $v=0$ із (9) одержуємо кубічне рівняння:

$$
\begin{aligned}
& a_{j}^{3}-a_{j-1} a_{j}^{2}+\left(a_{j-1}^{2}+\frac{2 \omega^{2}}{\lambda}\right) a_{j}- \\
& -\left(\frac{4 f g}{\lambda}-\frac{2 \omega^{2}}{\lambda} a_{j-1}-a_{j-1}^{3}\right)=0 .
\end{aligned}
$$

Щоб знайти аналітичні розв'язки рівняння (10) потрібно обчислити допоміжні величини:

$$
\begin{gathered}
Q_{j}=\frac{1}{2}\left(\frac{4 f g}{\lambda}-\frac{20}{27} a_{j-1}^{3}-\frac{4}{3} \frac{\omega^{2}}{\lambda} a_{j-1}\right) ; \\
P_{j}=-\frac{1}{9}\left(2 a_{j-1}^{2}+\frac{6 \omega^{2}}{\lambda}\right) .
\end{gathered}
$$


Якщо виявляється, що $Q_{j}^{2}-P_{j}^{3} \geq 0$, то корінь подається виразом:

$$
\begin{gathered}
a_{j}=\frac{a_{j-1}}{3}+\sqrt[3]{\sqrt{Q_{j}^{2}-P_{j}^{3}}-Q_{j}}- \\
-\sqrt[3]{\sqrt{Q_{j}^{2}-P_{j}^{3}}+Q_{j} .}
\end{gathered}
$$

У випадку, коли $Q_{j}^{2}-P_{j}^{3}<0$, обчислення $a_{j}$ доводиться проводити за формулами:

$$
\begin{gathered}
a_{j}=\frac{a_{j-1}-\beta_{j}}{2}+ \\
+\sqrt{-\frac{2 \omega^{2}}{\lambda}-3 \frac{\left(a_{j-1}-\beta_{j}\right)^{2}}{4}-a_{j-1} \beta_{j} ;} \\
\beta_{j}=2 \sqrt{P_{j}} \cos \left(\frac{A_{j}}{3}\right)+\frac{a_{j-1}}{3} ; \\
A_{j}=\pi-\arccos \frac{Q_{j}}{\sqrt{P_{j}^{3}}}
\end{gathered}
$$

Із наближених способів обчислення амплітуд розмахів укажемо метод простих ітерацій на базі співвідношення:

$$
\underset{k=1,2,3, \ldots,}{a_{* k} \approx a_{j-1} \frac{2 f g}{\omega^{2}+\frac{\lambda}{2}\left(a_{j-1}^{2}+a_{j k-1}^{2}\right)} ;}
$$

Компактна формула (13) придатна для розрахунків, як при $\lambda>0$, так і при $\lambda<0$. У випадку лінійної пружини із (13) випливає відома залежність:

$$
a_{j}=a_{j-1}-\frac{2 f g}{\omega^{2}} .
$$

Обчислення тривалості розмахів. Виходячи з того, що тривалість $t_{j}$ j-го розмаху подається інтегралом:

$$
t_{j}=\int_{-a_{j}}^{a_{j}} \frac{d x}{|v|} .
$$

Після підстановки (9) в (14), одержуємо:

$$
=\int_{-a_{j}}^{a_{j}} \frac{t_{j}=\frac{1}{\sqrt{2}} I\left(a_{j-1}, a_{j}\right)=}{\sqrt{\frac{\lambda}{4}\left(a_{j-1}^{4}-x^{4}\right)+\frac{\omega^{2}}{2}\left(a_{j-1}^{2}-x^{2}\right)-f g\left(a_{j-1}+x\right)}}
$$

При $\lambda=0$ можливе аналітичне обчислення $I\left(a_{j-1}, a_{j}\right)$. Воно призводить до відомої формули:

$$
t_{j}=\frac{\pi}{\omega}
$$

Коли тривалість всіх розмахів одинакові і не залежать від амплітуд розмахів та від стартового відхилення $a_{0}$.

Ця синхронність коливань порушується для нелінійно пружної системи. При $\lambda \neq 0$ значення $I\left(a_{j-1}, a_{j}\right)$ доводиться знаходити чисельними методами на комп'ютері. Варто звернути на те, що інтеграл $I\left(a_{j-1}, a_{j}\right)$ відноситься до невласних інтегралів другого роду, бо підінтегральна фрункція має особливості при $x=a_{j-1}$ і $x=a_{j}$. Щоб усунути сингулярності, виконаємо наступні перетворення. Подамо інтеграл сумою двох доданків:

$$
I\left(a_{j-1}, a_{j}\right)=I\left(a_{j-1}, 0\right)+I\left(0, a_{j}\right),
$$

де:

$$
\begin{gathered}
I\left(a_{j-1}, 0\right)=\int_{-a_{j-1}}^{0} d x \cdot\left(a_{j-1}+x\right)^{-\frac{1}{2}} \times \\
\times d x \cdot\left[\frac{\lambda}{4}\left(a_{j-1}^{2}+x^{2}\right)\left(a_{j-1}-x\right)+\right. \\
\left.+\frac{\omega^{2}}{2}\left(a_{j-1}-x\right)-f g\right]^{-\frac{1}{2}}
\end{gathered}
$$

$$
\begin{aligned}
& I\left(0, a_{j}\right)=\int_{0}^{a_{j}} d x \cdot\left(\frac{\lambda}{4}\left(a_{j-1}^{4}-x^{4}\right)+\right. \\
& \left.+\frac{\omega^{2}}{2}\left(a_{j-1}^{2}-x^{2}\right)-f g\left(a_{j-1}+x\right)\right)^{-\frac{1}{2}}
\end{aligned}
$$

Уведенням нової змінної $a_{j-1}+x=\xi^{2}$ першому з них надаємо вигляд:

$$
\begin{gathered}
I\left(a_{j-1}, 0\right)=2 \int_{0}^{\sqrt{a_{j-1}}} d \xi \cdot\left(\left(2 a_{j-1}-\xi^{2}\right) \times\right. \\
\left.\left[\frac{\lambda}{4}\left(a_{j-1}^{2}+\left(\xi^{2}-a_{j-1}\right)^{2}\right)+\frac{\omega^{2}}{2}\right]-f g\right)^{-\frac{1}{2}}
\end{gathered}
$$
вираз:

Віднявши під коренем у другому інтегралі

$$
\frac{\lambda}{4}\left(a_{j-1}^{4}-a_{j}^{4}\right)+\frac{\omega^{2}}{2}\left(a_{j-1}^{2}-a_{j}^{2}\right)-f g\left(a_{j-1}+a_{j}\right)=0,
$$

його зводимо до квадратури:

$$
\begin{gathered}
I\left(0, a_{j}\right)=\int_{0}^{a_{j}} d x \cdot\left(\left(a_{j-1}-x\right) \times\right. \\
\times\left[\frac{\lambda}{4}\left(a_{j}^{2}+x^{2}\right)\left(a_{j}+x\right)+\right. \\
\left.\left.+\frac{\omega^{2}}{2}\left(a_{j}+x\right)\right]+f g\right)^{-\frac{1}{2}}
\end{gathered}
$$


Щоб позбавитись сингулярності вводимо змінну $a_{j}-x=\eta^{2}$. Тоді:

$$
\begin{aligned}
& I\left(0, a_{j}\right)=2 \int_{0}^{\sqrt{a_{j}}} d \eta \cdot\left(\left(2 a_{j}-\eta^{2}\right) \times\right. \\
& \left.\times\left[\frac{\lambda}{4}\left(a_{j}^{2}+\left(a_{j}-\eta^{2}\right)^{2}\right)+\frac{\omega^{2}}{2}\right]+f g\right)^{-\frac{1}{2}}
\end{aligned}
$$

Інтеграли (15) і (16) можна обчислювати будь-яким методом на комп'ютері.

Якщо поступитися точністю визначення $t_{j}$, то тривалість ј-го розмаху можна знайти за фрормулою:

$$
t_{j}=\frac{\pi}{\sqrt{\omega^{2}+\frac{3}{16} \lambda\left(a_{j-1}+a_{j}\right)^{2}}} .
$$

При такому розрахунку відпадає потреба проводити чисельне інтегрування в (15), (16) на комп'ютері.

В доповнення до (17) можна запропонувати двобічні оцінки $t_{j}$.

У випадку жорсткої характеристики пружності, коли $c_{2}>0$, виконуються нерівності:

$$
t_{j}^{*}<t_{j}<\frac{\pi}{\omega} .
$$

Тут

$$
t_{j}^{*}=\frac{\pi}{\sqrt{\omega^{2}+0,75 \cdot \lambda \cdot a_{j-1}^{2}}} .
$$

Якщо характеристика пружності м'яка, тобто $c_{2}<0$, то:

$$
\frac{\pi}{\omega}<t_{j}<t_{j}^{* *}
$$

Тут

$$
t_{j}^{*}=\frac{\pi}{\sqrt{\omega^{2}-0,75|\lambda| a_{j-1}^{2}}} .
$$

Вище припускали, що коливання спричинені початковим відхиленням системи від положення рівноваги. Але одержані формули можна використати і в тому випадку, коли в положенні $x=0$ осцилятор миттєво отримає швидкість $v_{0}$. При цьому стала $c_{3}$ буде дорівнювати $\frac{1}{2} v_{0}$.

Швидкість руху осцилятора на проміжку $0 \leq x \leq a_{0}$ ставитиме:

$$
v(x)=\sqrt{2} \sqrt{\frac{1}{2} v_{0}^{2}-f g x-\frac{1}{2} \omega x^{2}-\frac{\lambda}{4} x^{4}} .
$$

Досягнувши максимального відхилення $x=a_{1}$, осцилятор зупиниться. Тому:

$$
v_{0}^{2}=2 f g a_{1}+\omega a_{1}^{2}+\frac{\lambda}{2} a_{1}^{4} .
$$

Цей вираз дозволяє досить просто обчислити ту початкову швидкість, що забезпечує задане стартове відхилення $a_{1}>a_{*}$. Якщо $a_{1}<a_{*}$, то осцилятор не вийде з області застою і його подальший коливальний рух неможливий. Задача дещо ускладнюється, коли треба знайти переміщення $a_{1}$ по заданому $v_{0}$. При такій постановці задачі рівняння (20) доводиться розв'язувати числовими методами.

\section{Числові результати і їх аналіз.}

Для проведення розрахунків приймаємо $m=1 \mathrm{\kappa} ; f=0,40775 ; a_{0}=0,05 \mathrm{м} ; c_{1}=10^{3} \mathrm{H} / \mathrm{M}$; $c_{2}= \pm 2 \cdot 10^{5} \mathrm{H} / \mathrm{M}^{3}$.

Обчислимо ширину області застою. Для вказаних числових даних по формулах (4)-(6) знаходимо, що $10^{3} a_{*}=4 ; 3,9873 ; 4,0129$ м, відповідно при $\lambda=0 ; \lambda>0 ; \lambda<0$. При м'якій характеристиці пружності ширина області застою дещо більша, ніж при жорсткій характеристиці, що впливає на кількість розмахів до повної зупинки осцилятора.

Результати обчислень $a_{*}$ методом ітерацій по формулі (7) записано в табл. 1. Початковим наближенням брали $a_{* 0}=0, k$ - номер ітерації.

Таблиця 1. Результати ітерацій по фрормулі (7)

\begin{tabular}{|c|c|c|c|c|}
\hline$k$ & 1 & 2 & 3 & 4 \\
\hline $\begin{array}{c}10^{3} a_{* k} \mathrm{M}, \\
\mathrm{np} n \lambda>0\end{array}$ & 4,0000 & 3,9872 & 3,9873 & 3,9873 \\
\hline $\begin{array}{c}10^{3} a_{* k} \mathrm{M}, \\
\mathrm{np} \boldsymbol{\lambda} \lambda<0\end{array}$ & 4,0000 & 4,0128 & 4,0129 & 4,0129 \\
\hline
\end{tabular}

Процес ітерацій швидко збігається, тому формула (7) зручна для проведення обчислень $a_{*}$.

Одержані за допомогою формули (11) амплітуди розмахів (з точністю до $10^{-5}$ ) записано в табл. 2. Для прийнятих вихідних даних необхідність використання формули (12) не виникала.

Таблиця 2. Амплітуди коливань при різних характеристиках пружності осцилятора

\begin{tabular}{|c|c|c|c|}
\hline \multirow{2}{*}{$j$} & $c_{2}>0$ & $c_{2}=0$ & $c_{2}<0$ \\
\cline { 2 - 4 } & \multicolumn{3}{|c|}{ Значення $10^{2} a_{j}, \mathrm{M}$} \\
\hline 1 & 4,4474 & 4,2000 & 3,6958 \\
\hline 2 & 3,8532 & 3,4000 & 2,6848 \\
\hline 3 & 3,2141 & 2,6000 & 1,7918 \\
\hline 4 & 2,5287 & 1,8000 & 0,9574 \\
\hline 5 & 1,7990 & 1,0000 & 0,1498 \\
\hline 6 & 1,0320 & 0,2000 & - \\
\hline 7 & 0,2409 & - & - \\
\hline
\end{tabular}

Кількість розмахів до повної зупинки осцилятора при $c_{2}>0$ виявилась більшою, ніж при $c_{2}<0$. Вона узгоджується з шириною області застою, що в табл. 1. 
Про швидкість збіжності ітерацій при обчисленні $a_{j}$ по фрормулі (13), при $c_{2}>0$ і $c_{2}<0$ надана в табл. 3 і в табл. 4. Там $k$ - номер ітерації, $j$ - номер амплітуди.

Таблиця 3. Результати ітерацій по формулі (13) при $c_{2}>0$

\begin{tabular}{|c|c|c|c|c|c|}
\hline \multirow{2}{*}{$k$} & $j=1$ & $j=2$ & $j=3$ & $j=4$ & $j=5$ \\
\cline { 2 - 6 } & \multicolumn{5}{|c|}{ Значення $100 a_{j k}, \mathrm{M}$} \\
\hline 1 & 4,4667 & 3,8742 & 3,2363 & 2,5511 & 1,8194 \\
\hline 2 & 4,4481 & 3,8539 & 3,2148 & 2,5294 & 1,7995 \\
\hline 3 & 4,4475 & 3,8532 & 3,2141 & 2,5287 & 1,7990 \\
\hline 4 & 4,4474 & 3,8532 & 3,2141 & 2,5287 & 1,7990 \\
\hline
\end{tabular}

Таблиця 4. Результати ітерацій по фоормулі (13) при $c_{2}<0$

\begin{tabular}{|c|c|c|c|c|c|}
\hline \multirow{2}{*}{$k$} & $j=1$ & $j=2$ & $j=3$ & $j=4$ & $j=5$ \\
\cline { 2 - 6 } & \multicolumn{5}{|c|}{ Значення $100 a_{j k}, \mathrm{M}$} \\
\hline 1 & 3,4000 & 2,5951 & 1,7501 & 0,9369 & 0,1424 \\
\hline 2 & 3,7390 & 2,6909 & 1,7933 & 0,9577 & 0,1498 \\
\hline 3 & 3,6890 & 2,6844 & 1,7918 & 0,9574 & 0,1498 \\
\hline 4 & 3,6969 & 2,6849 & 1,7918 & 0,9574 & 0,1498 \\
\hline 5 & 3,6956 & 2,6848 & 1,7918 & 0,9574 & 0,1498 \\
\hline 6 & 3,6958 & 2,6848 & 1,7918 & 0,9574 & 0,1498 \\
\hline
\end{tabular}

За початкове наближення приймали $a_{j 0}=a_{j-1}$, тобто $a_{10}=a_{0}, a_{20}=a_{1}$ і т.д. Збіжність ітерацій прискорюється зі збільшенням $j$.

Обчислення тривалості $t_{j}$ для лінійно пружного осцилятора, при $c_{2}=0$, дало $t_{j} \approx 0,099346 \mathrm{c}$ незалежно від $j$, що властиво для ізохронних коливань.

Результати обчислень $t_{j}$ при $c_{2}>0$ записано в табл. 5.

Таблиця 5. Значення $t_{j}^{*}$ i $t_{j}$ при $c_{2}>0$

\begin{tabular}{|c|c|c|c|c|c|}
\hline$j$ & $\begin{array}{c}100 t_{j}^{*}, \\
\mathrm{c}\end{array}$ & $\begin{array}{c}100 t_{j}, \\
\mathrm{c}\end{array}$ & $j$ & $\begin{array}{c}100 t_{j}^{*}, \\
\mathrm{c}\end{array}$ & $\begin{array}{c}100 t_{j}, \\
\mathrm{c}\end{array}$ \\
\hline 1 & 8,472 & $\frac{8,598}{8,599}$ & 5 & 9,490 & $\frac{9,570}{9,603}$ \\
\hline 2 & 8,724 & $\frac{8,848}{8,856}$ & 6 & 9,702 & $\frac{9,748}{9,789}$ \\
\hline 3 & 8,984 & $\frac{9,101}{9,117}$ & 7 & 9,856 & $\frac{9,863}{9,905}$ \\
\hline 4 & 9,244 & $\frac{9,347}{9,372}$ & - & - & - \\
\hline
\end{tabular}

В табл. 6 надана інформація про тривалість розмахів при $c_{2}<0$.

Значення $t_{j}$, записані в чисельниках, одержані чисельним інтегруванням квадратур (15) i (16) на комп'ютері. В знаменниках значення $t_{j}$ обчисленні за фрормулою (17). Розрахунки підтверджують виконання нерівностей(18) і (19). Зі збільшенням $j$ тривалості розмахів $t_{j}$ близькі до $\pi / \omega$, що мали при лінійній пружності осцилятора, коли ігнорували нелінійний додаток.

Таблиця 6. Значення $t_{j} \mathrm{i} t_{j}^{* *}$ при $c_{2}<0$

\begin{tabular}{|c|c|c|c|c|c|}
\hline$j$ & $100 t_{j}, \mathrm{c}$ & $100 t_{j}^{* *}, \mathrm{c}$ & $j$ & $100 t_{j}^{* *}, \mathrm{c}$ & $100 t_{j}, \mathrm{C}$ \\
\hline 1 & $\frac{12,068}{11,737}$ & 12,566 & 4 & $\frac{10,134}{10,078}$ & 10,183 \\
\hline 2 & $\frac{10,913}{10,793}$ & 11,141 & 5 & $\frac{10,003}{9,958}$ & 10,004 \\
\hline 3 & $\frac{10,403}{10,330}$ & 10,520 & - & - & - \\
\hline
\end{tabular}

Висновки. В зв'язку з нелінійною пружністю, тривалості розмахів осцилятора Дуфффінга залежать від амплітуд коливань. При зменшенні амплітуд коливань осцилятора з жорсткою характеристикою пружності зростають тривалості розмахів і зменшуються вони в осциляторі 3 м'якою характеристикою. В обох випадках вони наближаються до того значення тривалості напівциклу, що має лінійний осцилятор. Виведені формули дають можливість без використання другого інтегралу нелінійного рівняння коливань осцилятора обчислити його основні кінематичні характеристики, які змінюються в ході руху.

\section{Література}

1. Аврамов К. В. Нелинейная динамика упругих систем. Модели, методы, явления в 2 т. / К.В. Аврамов, Ю.В. Михмен. - Москва - Ижевск: Институт компьютерных исследований, 2015. $-\mathrm{T} 1$ - $716 \mathrm{c}$.

2. Пукач П. Я. Якісні методи дослідження нелінійних коливальних систем / П.Я. Пукач. Львів : Львівська політехніка, 2014. - 288 с.

3. Митропольский Ю. А. Избранные труды: в 2 т. / Ю. А. Митропольский. - Киев : Накова думка, 2012. - 504 c.

4. Шатохин В.М. Анализ и параметрический синтез нелинейных силовых передач машин / В.М. Шатохин. - Харьков: НТУ «ХПИ», 2008. $-456 \mathrm{c}$.

5. Ольшанський В.П. Коливання дисипативних осциляторів. / В.П. Ольшанський, Л.М. Тіщенко, С.В. Ольшанський та ін. - Харків : Міськдрук, 2015. $-116 \mathrm{c}$.

6. Ольшанський В.П. Динаміка дисипативних осциляторів. / В.П. Ольшанський, Л.М. Тіщенко, С.В. Ольшанський. - Харків: Міськдрук, 2016. $-264 \mathrm{c}$.

7. Ольшанський В. П. Вільні коливання пружно нелінійного осцилятора з сухим тертям / В. П. Ольшанський, В. В. Бурлака, М. В. Сліпченко // 
Інженерія природокористування. - 2019. - 4 (14). -C. 32 - 40.

8. Ольшанський В. П. Про затухання вільних коливань дисипативного осцилятора Дуфффінга / В.П. льшанський, В. В. Бурлака, М.В.Сліпченко. // Вісник Харківського національного технічного університету сільського господарства імені Петра Василенка: Проблеми надійності машин та засобів сільськогосподарського виробництва. - Харків: ХНТУСГ, 2019. - Вип. 205. - С. 55 - 64.

9. Ларин А. А. Очерки истории развития теории механических колебаний / А. А. Ларин. - Севастополь: Вебер, 2013. - 403 с.

10. Боголюбов Н. Н. Асимптотические методы в теории нелинейных колебаний / Н. Н. Боголюбов, Ю. А. Митропольский. - Москва: Наука, 1974. - 504 c.

11. Василенко М. В. Теорія коливань і стійкості руху / М. В. Василенко, О. М. Алексейчук. Київ : Вища школа, 2004. - 525 с.

12. Корн Г. Справочник по математике (для научных работников и инженеров) / Г. Корн, Т. Корн. - Москва: Наука, 1974. - 832 с.

\section{References}

1. Avramov K. V., Mikhmen Yu. V. (2015). Nelinejnaya dinamika uprugikh sistem. Modeli, metody', yavleniya $v 2 t$. T1. Moskva-Izhevsk : Institut kompyuternyh issledovanij, 716.

2. Pukach P. Ya. (2014). Yakisni metody doslidzhennya nelinijnyx kolyvalnyx system. Lviv : Lvivska politexnika, 288.

3. Mitropolskij Yu. A. (2012). Izbrannye trudy: v $2 t$. Kiev : Nakova dumka, 504.
4. Shatokhin V. M. (2008). Analiz i parametricheskij sintez nelinejnyh silovyh peredach mashin. Kharkov : NTU KhPl, 456.

5. Olshanskiy V. P., Tishhenko L. M., Olshanskiy S. V. and other. (2015). Kolyvannya dysypatyvnyh oscylyatoriv. Kharkiv : Mis`kdruk, 116.

6. Olshanskiy V. P., Tishhenko L. M., Olshanskiy S. V. (2016). Dynamika dysypatyvnyh oscylyatoriv. Kharkiv : Miskdruk, 264.

7. Olshanskiy V. P., Burlaka V. V., Slipchenko M. V. (2019). Vilni kolyvannya pruzhno nelinijnogo oscylyatora z suhym tertyam. Inzheneriya pryrodokorystuvannya, 4 (14), 32 - 40.

8. Olshanskiy V.P., Burlaka V.V., Slipchenko M.V. (2019). Pro zatuxannya vilnyh kolyvan dysypatyvnogo oscylyatora Duffinga. Visnyk Kharkivskogo nacionalnogo tehnichnogo universytetu silskogo gospodarstva imeni Petra Vasylenka: Problemy nadijnosti mashyn ta zasobiv sils kogospodarskogo vyrobnycztva, Vol. 205, $55-64$

9. Larin A. A. (2013). Ocherki istorii razvitiya teorii mekhanicheskikh kolebanij. Sevastopol : Veber, 403.

10. Bogolyubov N. N., Mitropol’skij Yu .A. (1974). Asimptoticheskie metody $v$ teorii nelinejnyh kolebanij. Moskva : Nauka, $504 \mathrm{~s}$.

11. Vasylenko M. V., Aleksejchuk O. M. (2004). Teoriya kolyvan`i stijkosti ruhu. Kyiv : Vyshha shkola, 525.

12. Korn G., Korn T. (1974). Spravochnik po matematike (dlya nauchny rabotnikov $i$ inzhenerov). Moskva : Nauka, 832.

\section{Аннотация}

\section{Свободные колебания осциллятора Дуффинга с сухим трением}

\section{В.П. Ольшанский, В.В. Бурлака, М.В. Слипченко}

Описаны свободные затухающие колебания осциллятора с сухим трением Кулона при наличии линейного и кубического слагаемых в выражении восстанавливающей силы, которая зависит от перемещения системы. Используя первый интеграл нелинейного дифференциального уравнения движения, определения точных значений амплитуд размахов сведено к вычислению соответствующих действительных корней кубического уравнения, которое имеет аналитическую реализацию. Для приближенного вычисления значений амплитуд предложена также дополнительная компактная итерационная формула. Удовлетворительная сходимость итераций по ней подтверждена многочисленными расчетами. Решена также задача определения длительностей размахов. Для этого переходом к новым переменным интегрирования несобственный интеграл второго рода сведено к сумме двух собственных интегралов, выражающих продолжительность размаха во времени. Их приходится интегрировать численными методами на компьютере. Поэтому дополнительно приведены неравенства двусторонней оценки длительностей размахов и предложена компактная формула, которая дает возможность приближенно вычислить эту продолжительность. Проведено сравнение числовых результатов, полученных различными способами. Показано, что затухание амплитуд колебаний, продолжительности размахов во времени их количество до полной остановки осциллятора зависят от характеристик нелинейности. Установлено, что в связи с нелинейной упругостью, продолжительности размахов осциллятора Дуфффинга зависят от амплитуд колебаний. От характеристик нелинейности также зависит и ширина области застоя осциллятора, определение которой сведено к вычислению действительного корня 
кубического уравнения по формулам Кардано. Выведены формулы, которые дают возможность без использования второго интеграла нелинейного уравнения колебаний осциллятора вычислить его основные кинематические характеристики, изменяющиеся в ходе движения.

Ключевые слова: свободные затухающие колебания, осциллятор Дуффринга, сухое трение, амплитуды размаха, продолжительность размахов, интегральные оценки.

\begin{abstract}
Free vibrations of Duffing oscillator with dry friction

\section{V.P. Olshanskiy, V.V. Burlaka, M.V. Slipchenko}

Free damped oscillations of an oscillator with dry Coulomb friction are described in the presence of linear and cubic terms in the expression of the restoring force, which depends on the displacement of the system. Using the first integral of the nonlinear differential equation of motion, determining the exact values of the amplitudes of the ranges is reduced to calculating the corresponding real roots of the cubic equation, which has an analytical implementation. For an approximate calculation of the amplitudes, an additional compact iterative formula is also proposed. The satisfactory convergence of iterations on it is confirmed by numerous calculations. The problem of determining the duration of the range is also solved. For this, a transition to new integration variables reduces the improper integral of the second kind to the sum of two eigen integrals expressing the duration of the range in time. They have to be integrated by numerical methods on a computer. Therefore, the inequalities of the two-sided estimation of the durations of the ranges are additionally presented and a compact formula is proposed that makes it possible to approximately calculate this duration. The numerical results obtained in various ways are compared. It is shown that the damping of the oscillation amplitudes, the duration of the amplitude over time, their number until the oscillator stops completely depend on the characteristics of nonlinearity. It is established that, due to nonlinear elasticity, the duration of the sweep of the Duffing oscillator depends on the amplitudes of the oscillations. The width of the oscillator stagnation region also depends on the nonlinearity characteristics, the definition of which is reduced to calculating the real root of the cubic equation using the Cardano formulas. Formulas are derived that make it possible, without using the second integral of the nonlinear equation of oscillation of the oscillator, to calculate its basic kinematic characteristics that change during movement.
\end{abstract}

Keywords: free damped oscillations, Duffing oscillator, dry friction, amplitude range, duration of the amplitude, integral estimates.

Бібліографічне посилання/ Bibliography citation: Harvard

Olshanskiy V.P., Burlaka V.V.and Slipchenko M.V. (2020) Free vibrations of Duffing oscillator with dry friction. Engineering of nature management, (1(15), pp. 82 - 88.

Подано до редакції / Received: 22.01.2020 